\title{
Análise das características e dos preceitos normativos da Política Nacional de Atenção Integral às Pessoas com Doenças Raras
}

Analysis of characteristics and normative precepts of the National Comprehensive Care Policy for People with Rare Diseases

\section{Adriana Modesto de Sousa ${ }^{1}$, Natan Monsores de Sá ${ }^{2}$}

Resumo: Este artigo aborda a Política Nacional de Atenção Integral às Pessoas com Doenças Raras. Objetivou-se analisar as características e preceitos normativos da referida Política a partir dos elementos percebidos como essenciais na construção e dinâmica de gestão de uma política de saúde. Para subsidiar as análises, foram recrutados ainda a Portaria no 981, textos normativos de Políticas Concorrentes e arcabouços teóricos pertinentes às Doenças Raras, Políticas Públicas e Advocacia em Saúde, sendo estes três eixos o Marco Conceitual deste estudo. Utilizou-se como metodologia a análise documental e o levantamento da literatura pertinente aos eixos elencados. Conclui-se que embora a Política Nacional de Atenção Integral às Pessoas com Doenças Raras contemple em suas diretrizes ações com vias a corrigir as lacunas dos serviços de saúde especializados por meio de incentivos e adequações profissionais, tanto o diagnóstico como a terapêutica requerem a efetivação das diretrizes que já orientam o Sistema Único de Saúde - SUS: universalidade, integralidade, equidade e descentralização. Destaca-se ainda que embora tenham sido observados os elementos objetivos e subjetivos essenciais na construção de uma política de saúde, é de fundamental importância que haja o espírito colaborativo de outras instâncias da gestão pública, assim como dos profissionais de saúde.

Palavras-chave: Políticas Públicas; Doenças Raras; Advocacia em Saúde.

Abstract: This article discusses the National Policy on Comprehensive Care for People with Rare Diseases. This study aimed to analyze the characteristics and normative precepts of that policy from the elements perceived as essential in building and dynamic management of a health policy. To support the analyzes were also recruited to Ordinance No. 981, normative texts of Competitors Policies and theoretical frameworks relevant to Rare Diseases, Public Policy and Health Advocacy, being these three axes the Conceptual Framework of the study. It was used as a document analysis methodology and the survey of the literature to listed axes. It is concluded that although the National Comprehensive Care Policy for People with Rare Diseases contemplates in its guidelines actions to correct the shortcomings of specialized health services through professional incentives and adjustments, both diagnosis and therapy require the execution of guidelines that have guided the Unified Health System - SUS: universality, comprehensiveness, equity and decentralization. It is noteworthy that even though they have been subject to the objective and subjective elements essential in building a health policy, it is of fundamental importance that there is the collaborative spirit of other bodies of public administration, as well as health professionals.

Keywords: Health Policies; Rare Diseases; Health Advocacy.

\footnotetext{
${ }^{1}$ Mestre em Ciências da Saúde (UnB), Especialista em Gestão de Saúde (UnB) e Docência Superior (FALBE) e Graduada em Letras - Português (UnB) e Saúde Coletiva (UnB). E-mail:anairdamodesto@gmail.com

${ }^{2}$ Doutor em Bioética (UnB), Mestre em Ciências da Saúde (UnB) e Graduado em Ciências Biológicas (UnB). Professor Adjunto da Faculdade de Ciências da Saúde - UnB. E-mail: natanmonsores@gmail.com
} 
Resumen: Este artículo aborda la Política Nacional de Atención Integral a Personas con Enfermedades Raras. Este estudio tuvo como objetivo analizar las características y los preceptos normativos de que la política de los elementos percibidos como esenciales en la construcción y gestión dinámica de una política de salud. Para apoyar los análisis también fueron reclutados a la Ordenanza № 981, los textos normativos de Competidores Políticas y marcos teóricos pertinentes a las Enfermedades Raras, Políticas Públicas y Salud Abogacía, y estos tres ejes del marco conceptual del estudio. Se utilizó como metodología para documentar el análisis y estudiar la literatura a los ejes mencionados. Llegamos a la conclusión de que a pesar de la Política Nacional de Atención Integral a Personas con Enfermedades Raras contempla en sus directrices comparte maneras de corregir las deficiencias de los servicios especializados de salud a través de incentivos y ajustes profesionales, tanto en el diagnóstico y la terapia requieren la ejecución de directrices que han guiado el Sistema Único de Salud - SUS: universalidad, integralidad, equidad y descentralización. Es de destacar que a pesar de que han sido objeto de los elementos objetivos y subjetivos esenciales en la construcción de una política de salud es de importancia fundamental que es el espíritu de colaboración de otros órganos de la administración pública, así como profesionales de la salud.

Palabras-Ilave: Política Pública; Enfermedades Raras; Defensa de la Salud.

\section{Introdução}

O presente artigo aborda a Política Nacional de Atenção Integral às Pessoas com Doenças Raras, instituída por meio da Portaria nำ 199, de 30 de janeiro de 2014 (BRASIL, 2014c). Para subsidiar a análise das características e preceitos normativos inerentes à referida Política, foram recrutados também a Portaria no 981 (BRASIL, 2014b) que altera, acresce e revoga dispositivos da Portaria no 199, textos normativos de Políticas Concorrentes $^{3}$ e, por meio da revisão da literatura, arcabouços teóricos pertinentes às Doenças Raras, Políticas Públicas e Advocacia em Saúde, compondo estes três últimos, o marco conceitual do estudo.

A escolha da análise da Política Nacional de Atenção Integral às Pessoas com Doenças Raras deu-se em razão de sua iminente construção, possibilitando perscrutar também os processos que a orientaram, assim como seus partícipes.

A análise dos elementos da referida Política contemplando suas características e preceitos normativos, abre precedentes para que novos estudos venham ratificar/refutar sua efetividade e/ou que seu processo construtivo possa servir de inspiração para a elabo-

\footnotetext{
${ }^{3}$ Políticas que corroboram ou impactam para a efetividade de outra política. Concorrem positivamente para seu sucesso de forma direta ou indireta.
} 
boração de outras políticas, tendo em vista a verificação de uma forte participação social respaldada por elementos constituintes da Advocacia em Saúde.

O Objetivo do estudo foi analisar as características e preceitos normativos da Política Nacional de Atenção Integral às Pessoas com Doenças Raras. Tendo em vista o referido anseio, foram estabelecidos como parâmetros os elementos percebidos como essenciais na construção e dinâmica de gestão de uma política de saúde, definidos por Fleury e Ouverney (2012).

\section{Doenças Raras}

Em 30 de janeiro de 2014, o Governo Federal promulgou a Portaria oo 199 que institui a Política Nacional de Atenção Integral às Pessoas com Doenças Raras, aprova as Diretrizes para Atenção Integral às Pessoas com Doenças Raras no âmbito do Sistema Único de Saúde (SUS), e institui incentivos financeiros de custeio (BRASIL, 2014c). Destaca-se que para efeito da referida Portaria, considera-se doença rara aquela que afeta até 65 pessoas em cada 100.000 indivíduos.

Em 21 de maio de 2014, é promulgada a Portaria o 981 (BRASIL, 2014b) que altera, acresce e revoga dispositivos da referida Portaria ㄲo 199. A partir da sucessão da descrita produção legislativa, infere-se tratar-se de fase de acomodação da recéminstituída "Política das Doenças Raras". Tal inferência decorre da apreciação do modus operandi e da forma com que as diretrizes que orientaram a Política foram azeitadas pelos partícipes envolvidos em sua construção, conforme apurado em estudo realizado por Fonseca (2014).

Ainda na perspectiva de cotejamento dos marcos legais resgata-se como precedente a Portaria no 81, de 20 de janeiro de 2009, que institui, no âmbito do Sistema Único de Saúde (SUS), a Política Nacional de Atenção Integral em Genética (BRASIL, 2009). Tal menção se faz necessária uma vez que $80 \%$ das Doenças Raras (DR) têm origem genética.

A preocupação de alguns atores sociais com a necessidade de adequação dos serviços de saúde às especificidades e peculiaridades do vasto rol de DR estimado entre 5.000 e 8.000 (PORTUGAL, 2008) não se restringe ao contexto brasileiro. Citam-se, à guisa de ilustração, o Programa Nacional Português para Doenças Raras (PORTUGAL, 2008 e o Plano Nacional Francês para Doenças Raras (FRANÇA, 2004). 
Embora não se postule uma abordagem comparativa, no âmbito do aporte estatal, no que se refere às ações e panorama das DR de forma ampla, convém destacar que as legislações vigentes em outros países como Estados Unidos e membros da União Europeia são orientadas, entre outras, pelas diretrizes do Orphan Drug Act (ODA) de 1983 - observadas emendas aprovadas posteriormente (ESTADOS UNIDOS, 1983) e pela Resolution EC no 141/2000 (UNIÃO EUROPEIA, 2000).

Tal menção traz à tona um ponto nevrálgico para a assistência: o desenvolvimento por parte da indústria farmacêutica de "drogas órfãs" e respectivo acesso. A referida categoria de medicamentos é caracterizada pelo baixo potencial mercadológico, o que faz com que os laboratórios resfoleguem ante os investimentos.

$\mathrm{Na}$ tentativa de driblar a timidez da indústria farmacêutica no desenvolvimento de "drogas órfãs", os marcos regulatórios dos países mencionados preveem modalidades de incentivo (ESTADOS UNIDOS, 1983; UNIÃO EUROPEIA, 2000; WIEST; BALBINOTTO NETO e CIPRIANI, 2014).

Wiest, Balbinotto Neto e Cipriani (2014) destacam o processo longo, custoso e arriscado no desenvolvimento de medicamentos. Os órfãos atendem a pequena parcela reduzindo a expectativa de lucros o que acaba por reclamar pela adoção de incentivos econômicos entre outros.

Corroborando ao enfatizado por estes autores, Silva (2000) salienta que o que desperta a pulsão das indústrias farmacêuticas para a realização de pesquisas e a comercialização de medicamentos são a demanda de determinadas doenças e seu potencial mercadológico. Desta forma, há a concentração da produção em determinadas linhas e o desinteresse por outras. Recorrentemente, o desinteresse recai sobre medicamentos voltados para doenças raras ou com preços controlados pelo governo. Isto implica dizer que o investimento e a oferta de um determinado medicamento por vezes não estão relacionados com seu potencial terapêutico, mas sim com variáveis extrínsecas à própria patologia. Outro elemento resgata a ética em pesquisa e a padronização dos protocolos clínicos, considerando: "A incorporação de novas tecnologias, insumos, equipamentos e medicamentos envolve, além de aspectos econômicos e orçamentários, aspectos morais e éticos [...]". (BRASIL, 2010). 
Alternativamente, Wiest, Balbinotto Neto e Cipriani (2014) referem-se à prática observada nos procedimentos padrão para incorporação de nova tecnologia nas legislações de países pesquisados pelos autores. Conforme apurado, a fase de desenvolvimento de um medicamento pode levar até sete anos, majorando o tempo e o custo do investimento. Desta forma, para minimizar o panorama moroso e dispendioso, as agências reguladoras desenvolvem protocolos direcionados às empresas com vias a facilitar a comprovação da eficácia do medicamento, premissa básica para a comercialização, gerando impacto sobre os custos totais no desenvolvimento dos medicamentos.

A este respeito Souza et. al (2010) ainda chamam a atenção para o fato de que os descritos incentivos podem acabar por estimular o monopólio das indústrias farmacêuticas, tornando os medicamentos órfãos bastante lucrativos estando em desacordo com a definição inicial de medicamento órfão.

Percebe-se a variedade de elementos que concorrem para a delimitação das diretrizes que comporão uma política. São por vezes elementos extrínsecos à ambiência estatal, mas com sensibilidade às suas ações visando à atenuação das tensões entre os interesses que podem, ocasionalmente, marchar por veredas distintas.

Compõem-se, a partir destas contribuições, dilemas pertinentes ao custo, desenvolvimento tecnológico e à ética. Todas estas variáveis precisam ser mensuradas na confecção de uma política.

Caráter suis generis parece ser a tônica das DR passando pela construção da categoria à força observada junto aos movimentos sociais, capazes de mobilizar a sociedade como um todo, contando, inclusive, com o aporte das redes sociais. Assim, a discussão em torno de sua Política deve prever também aspectos como o 'social assistencial" (necessidades oriundas de características etiológicas das doenças e a capacidade estatal de supri-las), „educacional" (adequação dos recursos humanos já inseridos no Sistema com vias à atuação especializada e observação da Genética Médica nos cursos de graduação em saúde, consorte ao preconizado pelas Diretrizes Curriculares Nacionais (DCN) da formação superior em saúde) e "econômico" (medicamentos, equipamentos, procedimentos e tecnologias indispensáveis ao paciente).

No concernente ao último aspecto, Souza et al. (2010) atentam para o desafio de se estabelecer parâmetros capazes de avaliar em termos técnicos e éticos os reais benefícios terapêuticos, considerando as prioridades em saúde. 
No universo das DR são inúmeros os desafios, regularmente catapultados por fatores limitantes inerentes à patologia e à assistência entre os quais se destacam: a dificuldade de diagnóstico, tornando-o tardio; a progressão das doenças por vezes degenerativas e incapacitantes ou que evoluem para óbito; a diversidade das DR; a timidez da indústria farmacêutica no desenvolvimento de pesquisas; a diversidade dos fatores de risco: agentes infecciosos, tóxicos, entre outras causas, além da origem genética. (PORTUGAL, 2008; CLARK e CLARK, 2012; WIEST, BALBINOTTO NETO e CIPRIANI, 2014).

Consorte ao exposto, destaca-se não haver consenso na conceituação de DR. A este respeito Wiest, Balbinotto Neto e Cipriani (2014) lembram que esta ausência dificulta a implantação de políticas efetivas no diagnóstico precoce e tratamento adequado. As implantações destas políticas impactariam na prospecção de investigações e novas pesquisas.

Embora nem todas as patologias raras possam ser prevenidas, os Serviços de Aconselhamento Genético (SAG) podem alargar o arco da atenção. No entanto, em estudo realizado por Grossi et al. (2009) os autores revelam que 59,1\% dos SAG no Brasil estão concentrados na Região Sudeste. A Região Norte encontra-se na orfandade deste tipo de atenção. Ressaltam-se, ainda, o impacto econômico e social que a triagem neonatal tem na prevenção de sequelas irreversíveis advindas de algumas doenças genéticas, reforçando a relevância desta modalidade de atenção (LUZ et al., 2008).

Corroborando ao exposto, Horovitz et al. (2006) chamavam a atenção quanto „a pequena importância dada ao aumento relativo dos defeitos congênitos no Brasil, frente à escassez de políticas públicas a elas relacionadas," Salienta-se, ainda, que em 2009, entrou em vigor a Portaria no 81 (BRASIL, 2009).

Por meio do levantamento das características da atenção relacionadas aos defeitos congênitos, Horovitz et al. (2006) chamam a atenção para o papel estratégico ocupado pelos hospitais universitários como a maior referência para o segmento de usuários com DR. No mesmo levantamento, constatou-se que a oferta do serviço está concentrada nas capitais, tendo seu reforço na Região Centro-Sul. No caso da Região Norte, verifica-se, praticamente, um vazio assistencial. 
De forma geral, há carência de geneticistas assim como fragilidade na relação referência/contra referência, colocando em xeque a diretriz integralidade. A demanda estimada é superior ao número de consultas efetivamente realizadas, ressaltando a possibilidade de viés no cômputo já que não se tratam de consultas inaugurais. A ausência de um cadastro único nacional impacta, ainda, na capacidade de oferta e otimização dos serviços.

$\mathrm{Na}$ escalada de limitações, foram observados pacientes com defeitos congênitos internados em unidades sem geneticistas, colocando a diretriz equidade em suspeição. A descontinuidade da atenção também figurou entre os achados, além da dificuldade de mensurar o correto cômputo de pacientes com quadro de defeito congênito. Segundo os autores, „pacientes nascidos em hospitais recebem alta sem avaliação genética, o que pode, futuramente, acarretar em condutas inadequadas para tratamentos e comprometimento da qualidade de vida e agudização de quadros pré-existentes" (HOROVITZ et al., 2006).

É corolário, portanto, a restrição da natureza da oferta dos serviços sendo os tipos de testes genéticos aqueles mais comumente disponibilizados As apreciações deixam clara a relevância da integralidade e da equidade junto aos serviços. A Portaria $n^{\circ}$ 81, que institui, no âmbito do Sistema Único de Saúde (SUS), a Política Nacional de Atenção Integral em Genética Clínica (BRASIL, 2009) ensaiou uma tentativa de mitigar o panorama poroso desta modalidade de atenção.

Ainda acerca do recorte genético, Novoa e Burnham (2011) ressaltam que a genética já ocupa espaço no SUS desde 1989, existindo programas há mais de 20 anos organizados pelo Ministério da Saúde e/ou entidades sem fins lucrativos em atenção a demandas sociais.

Assumindo a leitura de que as políticas são produto da ressonância das demandas sociais, destaca-se o fato de que os segmentos organizados tendem a perceber maior permeabilidade nos espaços reservados à „participação social", espaços estes chancelados pela Lei 8.142/90 (BRASIL, 1990), que dispõe sobre a participação da comunidade na gestão do Sistema Único de Saúde (SUS) e sobre as transferências intergovernamentais de recursos financeiros na área da saúde e dá outras providências; e o Decreto nº 8.243, 
de 23 de maio de 2014, que Institui a Política Nacional de Participação Social (PNPS) e o Sistema Nacional de Participação Social (SNPS), e dá outras providências, entre outras letras normativas (BRASIL, 2014a).

Embora a leitura da categoria Doenças Raras esteja calcada em fatores como prevalência e heterogeneidade, cuja referência é a patologia (frequência e etiologia), Oliveira, Guimarães e Machado (2012) chamam a atenção para a "identidade" individual/coletiva cujo foco é permutado para o binômio sujeito/sujeitos. Estes autores têm como mote para futuras pesquisas, desvendar o que faz com que um conjunto heterogêneo de associações se configure em coalisão bem definida, capaz de mobilizar e converter suas demandas em prioridade no âmbito da saúde pública.

Pertinente ao supracitado, mais adiante será tratado o eixo Advocacia em Saúde, estratégia social em que os referidos atores sociais encontram espaço profícuo à atuação legitimando seus pleitos.

A resposta para o questionamento lançado por Oliveira, Guimarães e Machado (2012) e os demais, podem ensejar condição de pedra filosofal à Política estudada transmutando sofrimento e adversidade em dignidade e melhor qualidade de vida.

\section{Políticas Públicas}

Para a apreciação da Política das Doenças Raras é necessário situar o que seja uma política pública. Ressalva-se o vocábulo "pública", pois a natureza do vocábulo "política" já remete ao que é público, tratando-se de pleonasmo. Rua (2014) esclarece:

As políticas públicas (policies), por sua vez, são outputs, resultantes da atividade política (politics): compreendem o conjunto das decisões e ações relativas à alocação imperativa de valores. Nesse sentido é necessário distinguir entre política pública e decisão política. Uma política pública geralmente envolve mais do que uma decisão e requer diversas ações estrategicamente selecionadas para implementar as decisões tomadas. Já uma decisão política corresponde a uma escolha dentre um leque de alternativas, conforme a hierarquia das preferências dos atores envolvidos, expressando - em maior ou menor grau - uma certa adequação entre os fins pretendidos e os meios disponíveis.

Infere-se que, uma política pública é o produto de um conjunto de intenções provenientes de demandas e interesses sociais, ratificado por produção normativa. O que se configura como interesse público não é consolidado desde sua gênese, é fruto de um processo de construção. Tampouco, se pode de maneira categórica separar como 
elementos excludentes o interesse público e os interesses privados. Não é possível encontrar interesse público fora do conjunto dos interesses privados. Neste sentido, é que se legitimam os pleitos de segmentos específicos para além dos direitos difusos ${ }^{4}$. Patri (2011) ressalta:

Políticas Públicas, de uma forma simples e objetiva, podem ser definidas como ações que o governo, representando o estado, decide fazer ou não, dentre as alternativas propostas, tomadas a serviço do interesse público ou coletivo da sociedade.

Patri (2011) ainda destaca que os partícipes dos processos de construção de políticas públicas são, de um lado, representantes da sociedade civil; e, do outro lado, os representantes do Estado - inseridos na máquina pública de forma direta ou indireta por rede de influências. É nesta pluralidade representativa, onde devem ser buscados os consensos, driblando os dissensos.

A Política das Doenças Raras não se refere aos direitos difusos. É, em sua extensão, um direito individual/coletivo, tendo como caixa de ressonância de sua construção o consórcio das vozes dos atores sociais que lançaram mão da Advocacia em Saúde. Em contexto democrático estes diversos atores sociais compõem o repertório de players (PATRI, 2011).

\section{Advocacia em Saúde}

Na língua portuguesa não há, ainda, uma tradução consolidada para o termo inglês advocacy. No entanto, para efeito deste estudo, adotou-se o termo utilizado de forma mais recorrente: Advocacia em Saúde. Sua gênese remete à defesa de interesses e engajamento ativo pertinentes à uma causa.

Dallari et al. (1996) ressaltam:

[...] o termo advogar, tradicionalmente usado apenas para designar a atividade profissional do bacharel em direito regularmente licenciado, passa, também, a conformar uma nova expressão: a advocacia em saúde, significando a reivindicação pelo direito à saúde.

\footnotetext{
${ }^{4}$ Direitos difusos são todos aqueles que não são atribuídos a um grupo específico, pois dizem respeito a toda a sociedade.
} 
Ainda para os mesmos autores (1996):

A advocacia em saúde baseia-se no princípio de que as pessoas têm direitos básicos positivados juridicamente, ou não positivados, que são desrespeitados ou não garantidos. [...] não basta que o direito à saúde e suas garantias estejam expressos em documentos é necessário torná-lo um direito garantido de fato.

Para a promoção de mudanças políticas é requerida a identificação de um problema, a proposição de mudanças e a Advocacia em Saúde. Neste sentido, a atuação do Grupo de Trabalho (GT) e o GT ampliado de Doenças Raras, instituído pelo Ministério da Saúde, objeto de estudo já mencionado (FONSECA, 2014), cujo objetivo foi de definir os principais pontos para a construção da Política (BRASIL, 2014c): constituição das linhas de cuidado, procedimentos a serem incorporados, rearranjados ou ampliados no âmbito do SUS, ao contar em seus espaços deliberativos com membros da sociedade civil, propiciou o incremento da Advocacia em Saúde, resgatando sua gênese americana, assim como a definição ofertada por Dallari et al. (1996).

Segundo os dados apurados por Fonseca (2014), o GT reuniu-se entre os meses de abril/novembro de 2012, sendo composto por três categorias de representação: gestores e equipe técnica ministerial, especialistas e associações/entidades de usuários. Chama-se a atenção para o elenco de especialistas, as Associações e entidades de usuários, sendo estes o braço não estatal do GT, corroborando para a necessidade de se contemplar neste estudo o eixo Advocacia em Saúde.

Germani e Aith (2013) enfatizam: "[...] é preciso pensar (e agir) na criação de uma rede de stakeholders, conceito amplamente usado no contexto empresarial, aqui traduzido e expandido para a ideia de pessoas-chave".

As associações e entidades de usuários partícipes foram o Instituto Baresi, a Aliança Brasileira Genética, Associação Maria Vitória (AMAVI), Associação Paulista dos Familiares e Amigos dos Portadores de Mucopolissacaridose, Federação Brasileira de Associações Civis de Portadores de Esclerose Múltipla (FEBRAPEM), Associação Brasileira de Síndrome de Ehlers-Danlos e Hipermobilidade, Instituo Canguru e Grupo Encontrar.

Ressalta-se, ainda, que no contexto dos momentos deliberativos foram definidos os parâmetros norteadores da nova Política: linhas de cuidados e procedimentos a serem incorporados no rol dos serviços disponibilizados pelo SUS. 
O produto desta construção contempla os objetos de análise propostos pelo presente artigo: Portaria no 199, que institui a Política Nacional de Atenção Integral às Pessoas com Doenças Raras (BRASIL, 2014c) e Portaria n 981 (BRASIL, 2014b) que altera, acresce e revoga dispositivos da Portaria nํ 199.

\section{Metodologia}

O método utilizado foi de natureza qualitativa com o aporte teórico na análise documental e levantamento da literatura pertinente aos eixos mencionados (SAKS; ALLSOP, 2011). A análise documental contemplou as Portarias n 199 e ํำ 981, assim como os perfis dos atores sociais que compuseram o grupo de trabalho que participou da construção da referida Política, a ata das reuniões e demais avanços já sinalizados, a partir do estudo realizado por Fonseca (2014).

Para analisar as características e preceitos normativos da Política Nacional de Atenção Integral às Pessoas com Doenças Raras e respectivas alterações, elegeu-se os elementos definidos por Fleury e Ouverney (2012). São eles: definição de objetivos (finalidades) da política; construção e o emprego de estratégias, planos, instrumentos e técnicas; desempenho simultâneo de papéis políticos e econômicos diferentes; construção oficial de arenas, canais e rotinas no âmbito dos processos decisórios; assimilação, contraposição e/ou compatibilização com demais projetos sociais em curso; desenvolvimento, reprodução e a transformação de marcos institucionais, que representam o resultado de referenciais valorativos, políticos e organizacionais e econômicos, que permeiam, sustentam a política e interligam ativamente o sistema de proteção social; e, a formação de referenciais éticos e valorativos da vida social.

Cabe ressaltar que o estudo não foi submetido ao comitê de ética em pesquisa, uma vez que todos os dados são de fonte secundária e de domínio público.

\section{Resultados}

Os parâmetros definidos por Fleury e Ouverney (2012) subsidiaram a análise a ser explanada. No entanto, convém destacar que estes parâmetros serviram de inspiração, não de determinação, uma vez que a configuração da Política solicita ao modelo proposto certa adaptação. Entretanto, não contamina a essência dos critérios elencados por aqueles autores. 
Para as análises propostas, foram elencados seis eixos: 1) Objetivos e finalidades da Política; 2) Construção e emprego de estratégias, planos, instrumentos e técnicas; 3) Papéis políticos e econômicos; 4) Arenas, canais e rotinas do processo decisório (construção normativa); 5) Assimilação, contraposição e/ou compatibilização de diferentes projetos sociais; 6) Referenciais éticos e valorativos que serão apresentados a seguir.

\section{Objetivos e finalidades da Política}

Os objetivos da Política encontram-se relacionados no art. 5ํ, incisos I a VI: I garantir a universalidade, a integralidade e a equidade das ações e serviços de saúde em relação às pessoas com doenças raras, com consequente redução da morbidade e mortalidade; II - estabelecer as diretrizes de cuidado às pessoas com doenças raras em todos os níveis de atenção do SUS; III - proporcionar a atenção integral à saúde das pessoas com doença rara na Rede de Atenção à Saúde (RAS); IV - ampliar o acesso universal e regulado das pessoas com doenças raras na RAS; V - garantir às pessoas com doenças raras, em tempo oportuno, acesso aos meios diagnósticos e terapêuticos disponíveis conforme suas necessidades; e VI - qualificar a atenção às pessoas com doenças raras.

A finalidade da Política é observada no art. $4^{\circ}$, que diz: „redução da mortalidade, contribuição para a redução da morbimortalidade e das manifestações secundárias e a melhoria da qualidade de vida das pessoas".

Os objetivos do referido instrumento de gestão resgatam princípios observados no art. 196 da CF/88 (BRASIL, 1988) e Lei 8.080/90 (BRASIL, 1990), ao tratarem da universalidade, integralidade e equidade da atenção, desta feita com o recorte das pessoas com DR.

\section{Construção e Emprego de Estratégias, Planos, Instrumentos e Técnicas}

Para o estabelecimento de estratégias, de planos, de instrumentos e técnicas, é sine qua non que haja uma situação problema, um panorama a ser corrigido, ou uma demanda a ser atendida. Dessa forma, o diagnóstico inicial desenhado traz os seguintes contornos: ausência de política específica; ineficiência do Estado em resposta às necessidades dos pacientes com doenças raras; porosidade dos serviços, dificuldade de acesso; fragilidade no binômio referência/contra referência; concentração dos serviços 
especializados em capitais; grandes centros e unidades de saúde específicas (hospitais universitários); descontinuidade da atenção; carência de recursos humanos especializados; procedimentos e dispensação de medicamentos órfãos; necessidade de incremento na formação continuação e acadêmica, com vias às especificidades inerentes ao ramo entre outras situações adversas.

Com intento de corrigir o panorama adverso exposto, a Política estudada elenca como objetivos macro os arts. 4ํe e 5ํㅡㄹ com redação já mencionada. Os núcleos temáticos contemplam ações de equidade, universalidade e integralidade, a partir de estratégias definidas nos art. 7ํㅡㄹ incisos: I - educação permanente de profissionais; II - promoção de ações intersetoriais e estabelecimento de parcerias; III - organização das ações e dos serviços; IV - ações que visem à habilitação/reabilitação, medidas assistivas para os casos que necessitem; V - diversificação das estratégias de cuidados; e VI - desenvolvimento de atividades no território com favorecimento da inclusão social e exercício da cidadania.

\section{Papéis Políticos e Econômicos}

O papel político enfatizado pode ser observado nos art. $6^{\circ}, 1$ - atenção humanizada e centrada nas necessidades; III - promoção do respeito às diferenças e aceitação de pessoas com DR, enfrentamento de estigmas e preconceitos; VII - acessibilidade. Também art. 7ํ, VI - promoção de autonomia e exercício da cidadania; art. 8ํ, VIII estímulo à participação e controle social; e art. 10, IX - implantar o acolhimento e a humanização (PNH).

O papel econômico encontra-se destacado nos art. 22 - incentivo financeiro de custeio mensal para equipes de Serviços de Atenção Especializada em DR, cuja natureza dos gastos é da ordem de $R \$ 11.650,00$ para equipes e $R \$ 5.750,00$ destinados a equipes excedentes e art. 23 - incentivo financeiro de custeio mensal para equipes profissionais de estabelecimentos de Referência em DR, cuja natureza dos gastos refere $R \$ 41.480,00$ destinados a equipes.

Ainda no concernente ao papel econômico, são sinalizados os art. 24 - incentivo financeiro para custeio de procedimentos e art. 26 - eventual complementação de recursos financeiros.

Conforme observado, são previstos incentivos financeiros para os estabelecimentos de saúde habilitados como Serviços de Atenção Especializada e de Referência em 
Doenças Raras. Consorte a estes incentivos o art. 26 prevê complementações. Os $\S^{\circ}{ }^{\circ}$ do art. 22 e $\S 2^{\circ}$ do art. 23 vinculam a destinação dos recursos ao segmento especificado. $O$ art. 24 trata do incentivo financeiro para o custeio dos procedimentos e Próteses e Materiais Especiais (OPM) -. Já o art. 29 recruta o monitoramento por parte do Sistema Nacional de Auditoria (SNA). Os incisos I e II do art. 30 tratam de recorte disciplinar: coercitivo de um lado, observância das pactuações por outro lado.

Estas variáveis tanto de custeio como de monitoramento são percebidas como pontos fortes à Política, no entanto, indaga-se: estes parâmetros serão capazes de equalizar as heterogeneidades pré-existentes no sistema e as pertinentes ao amplo espectro das DR?

\section{Arenas, Canais e Rotinas do Processo Decisório da Política (Construção Normativa)}

O cenário da construção da Política foi orientado pela participação de diversos atores, percebidos como players. A Política também experimentou mais de um momento/termômetro de negociação e pactuação intergovernamental, a saber:

- construção da nova política, constituição das linhas de cuidado e procedimentos a serem incluídos no rol do SUS, orientados pelas negociações e pactuações no contexto do Grupo de Trabalho (GT);

- normas para a Habilitação de Serviços de Atenção Especializada e Centros de Referência em Doenças Raras no Âmbito do SUS, definidos nos contextos das negociações e pactuações do Grupo de Trabalho de Atenção da Comissão Intergestores Tripartite (CIT/ MS), Conselho Nacional de Secretários de Saúde (CONASS) e Conselho Nacional de Secretarias Municipais de Saúde (CONASEMS); e

- Contribuições aos textos normativos, advindos de Consulta Pública ํo 7, de 10 de abril de 2013.

Conforme descrito, os espaços dos processos decisórios que subsidiaram a construção da Política das Doenças Raras contaram com a participação de uma plêiade de atores sociais, constituindo-se como produção plural. A pluralidade de atores é percebida como fortaleza à Política, no entanto, convém perscrutar acerca da paridade destas representações, posto que e como referido anteriormente, tratam-se de players. 


\section{Assimilação, Contraposição e/ou Compatibilização de Diferentes Projetos Sociais}

Para a apreciação do eixo 5, carece elencar a categoria do consórcio das políticas setoriais de saúde: Política de Proteção Social e Política Nacional de Atenção Integral às Pessoas com Doenças Raras, a estas estão vinculadas o que convencionou-se chamar de Políticas Concorrentes: Política Nacional de Regulação do SUS (Portaria nº 1.599/GM/MS); Política Nacional de Atenção Integral em Genética (Portaria no 81/GM/MS); Rede Cegonha (Portaria no 1.459/GM/MS); Política Nacional de Atenção às Urgências e Rede de Atenção às Urgências (Portaria no 1.600/GM/MS); Política Nacional de Atenção Básica (Portaria nº 2.488/GM/MS); Rede de Atenção Psicossocial (Portaria no 3.088/GM/MS); Rede de Cuidados à Pessoa com Deficiência no âmbito do SUS (Portaria no 793/GM/MS); Rede de Atenção à Saúde das Pessoas com Doenças Crônicas no âmbito do SUS (Portaria n² 252/GM/MS); e Política Nacional de Humanização.

As políticas concorrentes elencadas suscitam a seguinte indagação: a Política das Doenças Raras vem no sentido de ratificar o que já fora legitimado em sentido lato, ou as Políticas Concorrentes são o subsídio necessário para a efetivação desta, ressaltando ser ponto pacífico a apreciação de que a Política das Doenças Raras, tanto quanto às demais, necessitam arregimentar reforços extrínsecos a ela.

\section{Referenciais Éticos e Valorativos}

$\mathrm{O}$ art. 6을 incisos I, II, III, IV, V e VII, traz os referenciais éticos e valorativos preconizados pela Política das Doenças Raras, estes enfatizam: atenção humanizada; reconhecimento da patologia e necessidades inerentes à mesma; e respeito às diferenças, combate aos estigmas e preconceitos.

Parte das variáveis descritas constituem-se como subjetividades e, por vezes, fruto de exercícios individuais. Requer que neste aspecto, e para que haja a efetivação das mesmas, haja o desenvolvimento de ações junto aos profissionais de saúde na perspectiva da qualificação e sensibilidade com o segmento extravagante.

\section{Conclusões}

A Política das Doenças Raras (BRASIL, 2014c) nasce consorciada à outros textos normativos, definidos como Políticas Concorrentes. Infere-se, portanto, uma matriz anacrônica à Portaria no 199. Não se trata de um mal ajambrado de intenções, mas invocações necessárias à legitimidade da Lei. 
A necessidade do estabelecimento do binômio saúde/educação se materializa na perspectiva tanto da formação superior como na educação continuada, com foco nas DR. O espectro de saúde/educação alcança não só as especificidades das DR; mas,as, também, as lacunas ainda observadas entre o modelo de formação superior e as diretrizes do SUS, mesmo que as Diretrizes Curriculares Nacionais das graduações em saúde tenham sido definidas posteriormente à criação do Sistema..

Neste sentido, é sine qua non que se propiciem adequações nas práticas profissionais subsidiadas a partir de aprendizagens significativas (CARMO, 2010), capazes de aproximar o sujeito em formação ou já inserido no sistema, à realidade da atenção em saúde no Brasil e das diretrizes que orientam o SUS.

A literatura apurada revela lacunas existentes na oferta dos serviços no contexto brasileiro anterior à promulgação da Política, assim indaga-se acerca da capacidade de cada um dos entes da Federação de implantação das unidades especializadas e de referência em contextos já diversificados.

A condição de diagnóstico de doença rara ainda habita terreno nebuloso, mesmo no âmbito estatal, o que faz com que seja produto de pleito por parte dos doentes: adequações laborais e aposentarias especiais.

Verifica-se que para efetivar 0 art. $6^{\circ}$, inciso III, que trata do respeito às diferenças e o combate aos estigmas e preconceitos, requer o espírito colaborativo de outras pastas, reconhecendo-se que para a formação de referenciais éticos e valorativos da vida social há que recrutar o conceito de cidadania em todas as suas instâncias.

\section{Considerações finais}

Este artigo não pretende esgotar a discussão acerca da Política Nacional de Atenção Integral às Pessoas com Doenças Raras. Buscou-se salientar a necessidade de novos estudos que possam ilustrar o ciclo percorrido pela política, respondendo indagações propostas por Viana e Baptista (2012), no que se refere à clareza dos objetivos e metas, adequação e previsibilidade de recursos, estratégias de implementação, divisão de atribuições, características organizacionais e posicionamento dos atores sociais 
descritas nas Portarias ํㅜ 199 e Portaria ํㅜ 981, confrontando com as rotinas observadas no SUS.

Foram apresentadas as características e os preceitos normativos, referentes à Política Nacional de Atenção Integral às Pessoas com Doenças Raras, consubstanciados pelas apreciações dos eixos que compuseram o marco conceitual deste estudo, analisados de forma concisa à luz dos parâmetros avaliativos definidos por Fleury e Ouverney (2012).

A partir dos resultados das análises, faz-se um chamamento a novos estudos a partir de parâmetros supramencionados assim como para que pessoas diagnosticadas com doenças raras, a sociedade civil, gestores e pesquisadores; e que esses possam acompanhar o processo de implementação da política valendo-se do controle social e, complementarmente, seja arguida a percepção destes segmentos quanto à adequação às suas necessidades e correção de lacunas, aqui apontadas, como préexistentes/recorrentes no Sistema.

Acredita-se, por fim, que embora não tenha havido um acompanhado anacrônico dos processos que nortearam a construção da política, comprometendo uma análise mais robusta, alicerçada em dados primários, a possiblidade do estabelecimento da interface entre Saúde/Direito, cujo fio condutor foi a Advocacia em Saúde, poderá alargar o leque de possibilidades de análise, sinalizando assim, como ponto forte ao estudo, afluentes comuns e complementares entre um e outro ramo, impactando na leitura de tradicionais entreveros no âmbito da judicialização da saúde.

\section{Referências Bibliográficas}

BALBINOTTO NETO, G. e WIEST, R. e CIPRIANI, F. A economia das Doenças Raras: incentivos e regulação. Economic Analysis of Law Review - EALR, Brasília, v.5, n.1, p. 6998, 2014. Disponível em:

http://portalrevistas.ucb.br/index.php/EALR/article/viewFile/5\%20EALR\%2069/5\%20EALR \%2069. Acesso em: 20 ago. 2014.

BRASIL. Presidência da República. Decreto no 8.243, de 23 de maio de 2014. Institui a Política Nacional de Participação Social - PNPS e o Sistema Nacional de Participação Social - SNPS, e dá outras providências. Diário Oficial da República Federativa do Brasil, Brasília, DF, 26 de maio de 2014. Disponível em: http://www.planalto.gov.br/ccivil 03/ Ato2011-2014/2014/Decreto/D8243.htm. Acesso em: 20 ago. 2014. 
BRASIL. Ministério da Saúde. Portaria GM/MS no 981, de 21 de maio de 2014. Altera, acresce e revoga dispositivos da Portaria no 199/GM/MS, de 30 de janeiro de 2014, que institui a Política Nacional de Atenção Integral às Pessoas com Doenças Raras, aprova as Diretrizes para Atenção Integral às Pessoas com Doenças Raras no âmbito do Sistema Único de Saúde (SUS) e institui incentivos financeiros de custeio. Diário Oficial da República Federativa do Brasil, Brasília, DF, 21 de maio de 2014b. Disponível em: http://pesquisa.in.gov.br/imprensa/servlet/INPDFViewer?jornal=1\&pagina=44\&data=21/05/ 2014\&captchafield=firistAccess. Acesso em: 20 ago. 2014.

BRASIL. Ministério da Saúde. Portaria GM/MS nำ199, de 30 de janeiro de 2014. Institui a Política Nacional de Atenção Integral às Pessoas com Doenças Raras, aprova as Diretrizes para Atenção Integral às Pessoas com Doenças Raras no âmbito do Sistema Único de Saúde (SUS) e institui incentivos financeiros de custeio. Diário Oficial da República Federativa do Brasil, Brasília, DF, 21 de fevereiro de 2014c. Disponível em: http://pesquisa.in.gov.br/imprensa/jsp/visualiza/index.jsp?jornal=1\&pagina=44\&data=12/02/ 2014. Acesso em: 20 ago. 2014

BRASIL. Ministério da Saúde. Portaria no 81, de 20 de janeiro de 2009. Institui, no âmbito do Sistema Único de Saúde (SUS), a Política Nacional de Atenção Integral em Genética Clínica. Diário Oficial da República Federativa do Brasil. Brasília, DF, 21 de janeiro de 2009. Disponível em: http://www.sbgm.org.br/SBGM\%20PORTARIA\%20SUS.pdf. Acesso em: 20 ago. 2014.

BRASIL. Presidência da República. Lei 8.080, de 19 de setembro de 1990. Dispõe sobre as condições para a promoção, proteção e recuperação da saúde, a organização e o funcionamento dos serviços correspondentes e dá outras providências. Diário Oficial da República Federativa do Brasil. Brasília, DF, 20 de setembro de 1990. Disponível em: http://www.planalto.gov.br/ccivil 03/leis/l8080.htm. Acesso em: 20 ago. 2014.

BRASIL. Presidência da República. Lei 8.142, de 28 de dezembro de 1990. Dispõe sobre a participação da comunidade na gestão do Sistema Único de Saúde (SUS\} e sobre as transferências intergovernamentais de recursos financeiros na área da saúde e dá outras providências. Diário Oficial da República Federativa do Brasil. Brasília, DF, 31 de dezembro de 1990. Disponível em: http://www.planalto.gov.br/ccivil 03/leis//8142.htm. Acesso em: 20 ago. 2014.

BRASIL. Congresso Nacional. Constituição Federal, 05 de outubro de 1988. Diário Oficial da República Federativa do Brasil. Brasília, DF, 05 de outubro de 1988. Disponível em: http://www.senado.gov.br/legislacao/const/con1988/CON1988 05.10.1988/CON1988.pdf. Acesso em: 20 ago. 2014.

CARMO, J. dos S.. Fundamentos Psicológicos da Educação. Curitiba: IBPEX, 2010, 249 p.

CLARK, L. e CLARK, O. Shire. 12 p. Disponível em: http://www.evidencias.com.br/uploadlmages/01 doencas raras.pdf. Acesso em 20 ago. 2014. 
DALLARI, S.G. et al. Advocacia em saúde no Brasil contemporâneo. Revista Saúde Pública. São Paulo, v.30, n.6, p.592-601, 1996. Disponível em: http://www.scielo.br/pdf/rsp/v30n6/5117.pdf. Acesso em 07 set. 2014.

FLEURY, S. e OUVERNEY, A.M. Em: GIOVANELLA, L. [et al.] (orgs.) Políticas e Sistemas de Saúde no Brasil. Rio de Janeiro: FIOCRUZ, 2012, 1.100 p.

FONSECA, R. V. G. da. A construção de uma política pública para doenças raras no Brasil Brasília, Universidade de Brasília - UnB, Faculdade de Ciências da Saúde, 2014, 21 p. Disponível em: http://bdm.unb.br/handle/10483/8182. Acesso em: 20 ago.2014.

GERMANI, A. C. C. G. e AITH, F. Advocacia em promoção da saúde: conceitos fundamentos e estratégias para a defesa da equidade em saúde. Revista de Direito Sanitário. São Paulo, v.14, n.11, p. 34-59, 2013. Disponível em: http://www.revistas.usp.br/rdisan/article/view/56622/59639. Acesso em: 20 ago. 2014.

GROSSI, R [et al.] Serviços de Aconselhamento Genético: um panorama nacional. In: V CONGRESSO BRASILEIRO MULTIDISCIPLINAR DE EDUCAÇÃO ESPECIAL, 2009, Londrina - $\quad$ PR. http://www.uel.br/eventos/congressomultidisciplinar/pages/arquivos/anais/2009/327.pdf. Acesso em: 20 ago. 2014

HOROVITZ, D. D. G. [et al.]. Atenção aos defeitos congênitos no Brasil: características do atendimento e propostas para formulação de políticas públicas em genética clínica. Cadernos de Saúde Pública, Rio de Janeiro, v.22, n.12, p. 2599-2609, 2006. Disponível em: http://www.scielo.br/readcube/epdf.php?doi=10.1590/S0102311X2006001200010\&pid=S0102-311X2006001200010\&pdf path=csp/v22n12/09.pdf. Acesso em: 20 ago. 2014

LUZ, G. dos S.[et al.]. Prevalência das doenças diagnosticadas pelo Programa de Triagem Neonatal em Maringá, Paraná, Brasil: 2001-2006. Revista Gaúcha de Enfermagem. Porto Alegre, v.29, n.3, p.446-53, 2008. Disponível em: http://seer.ufrgs.br/RevistaGauchadeEnfermagem/article/view/6773. Acesso em: 20 ago. 2014

MINISTÉRIO DA SAÚDE. Ministério da Saúde - Secretaria de Atenção à Saúde. Protocolos Clínicos e Diretrizes Terapêuticas. Normas e Manuais Técnicos. Brasília, v. 1, p. 372, 2010.

NOVOA, M. C. e BURHHAM, T. F. Desafios para a universalização da genética clínica: o caso brasileiro. Rev. Panam Salud Publica. Washington, v. 29, n.1, p.61-68, 2011. Disponível em: http://www.scielosp.org/pdf/rpsp/v29n1/10.pdf . Acesso em: 20 ago. 2014

OLIVEIRA, C. R. C. e GUIMARÃES, M. C. S. e MACHADO, R. Doenças raras como categoria de classificação emergente: o caso brasileiro. DataGramaZero, v.13, n.1, 2012. Disponível em: http://dgz.org.br/fev12/F I art.htm. Acesso em: 20 ago. 2014 
PARLAMENTO EUROPEU E CONSELHO. Regulamento (CE) no 141/2000, de 16 de dezembro de 1999. Relativo aos Medicamentos Órfãos. Disponível em: http://ec.europa.eu/health/key documents/index en.htm. Acesso em: 20 ago. 2014.

PATRI, E. C. R. Relações Governamentais, Lobby e Advocacy no Contexto de Public Affairs. Organicom. Revista Brasileira de Comunicação Organizacional e Relações Públicas. São Paulo, v.8, n.14, 2011. Disponível em: http://revistaorganicom.org.br/sistema/index.php/organicom/article/view/397. Acesso em: 20 ago. 2014

PORTUGAL. Ministério da Saúde. Programa Nacional para Doenças Raras (PNDR). Junho de 2008. Disponível em: http://www.portaldasaude.pt/NR/rdonlyres/555DD3B3-45F0-4F74B633-28889E721BF1/0/i010420.pdf. Acesso em: 20 ago. 2014.

FRANÇA. Plano Nacional Francês para as Doenças Raras. Disponível em: http://www.eurordis.org/pt-pt/content/o-plano-nacional-da-franca-para-doencas-raras-0.

Acesso em: 20 ago. 2014.

REVISTA SAÚDE BRASIL. Saúde e Comunidade: Doenças Raras. Ano 2013. Disponível em: http://saudebrasilnet.com.br/publicacoes/revista-doencas-raras/. Acesso em: 20 ago. 2014.

RUA, M. das G.. Análise de Políticas Públicas: conceitos básicos. 17 p. Brasília. Disponível em: http://www.gestaoecidadania.com/2011/02/analise-de-politicas-publicas-conceitos.html Acesso em: 20 ago. 2014.

SAKS, M. e JUDITH, A. (orgs.). Pesquisa em saúde: métodos qualitativos, quantitativos e mistos. São Paulo: Roca, 2011.

SILVA, R.C.S. Medicamentos excepcionais no âmbito da assistência farmacêutica no Brasil. 2000. Dissertação de Mestrado em Saúde Pública. Escola Nacional de Saúde Pública da Fundação Oswaldo Cruz, Rio de Janeiro, 2000.

SOUZA, M. V. de [et al.] Medicamentos de alto custo para doenças raras no Brasil: o exemplo das doenças lisossômicas. Ciência \& Saúde Coletiva, Rio de Janeiro, v. 15, Supl. 3, p. 3443-3454, 2010.

THOMAS, M.T. The Orphan Drug Act and The Development of Products for Rares Diseases. U.S. Food and Drug Administration (FDA) - EUA. Disponível em: https://rarediseases.info.nih.gov/files/FDA\%200rphan\%20drugs.pdf. Acesso em: 20 ago. 2014. 
VIANA, A. L. d"A. e BAPTISTA, T. W. de F.. Análise de Políticas de Saúde. Em: GIOVANELLA, L. [et al.] (orgs.) Políticas e Sistemas de Saúde no Brasil. Rio de Janeiro, FIOCRUZ, 2012, $1.100 \mathrm{p}$.

Recebido para publicação em 20 de janeiro de 2015. Admitido para publicação em 15 de abril de 2015 